\title{
INFORMAL MEETING ON PHYSICS IN AGRICULTURE
}

Address of Mr. J. M. van Bonmel van Vloten, President of the Board of Governors of the Agricultural University at Wageningen, 7 September 1955

\section{Mr. Chairman, Ladies and Gentlemen,}

It is a great pleasure for me to extend a hearty welcome to you all and in particular to our guests from abroad on behalf of the Agricultural University at Wageningen.

More than fifty specialists from fourteen different countries are here together to participate in this Informal Meeting on Physics in Agriculture. Among them are physicists, chemists, meteorologists, botanists and agricultural engineers. If difference of outlook of the specialists in viewing a problem is a necessary condition to arrive at well-founded conclusions that can withstand criticism, the climate appears to be very favourable in this meeting. We may, therefore, expect that conclusions of a direct practical importance will be obtained in addition to the scientific results which through providing a better and more complete understanding of the phenomena will undoubtedly bear rich fruit for agriculture in the future.

The Food and Agriculture Organization of the United nations has been informed about the project and the Director of the Agriculture Division has welcomed the initiative and gives all good wishes for a successful meeting.

The main subject is without doubt of outstanding importance for agriculture in all parts of the world. To provide the necessary amount of water with which satisfactory yields can be obtained has been a problem which is probably as old as agriculture itself. Instead of considering it as a problem of a local character which must be solved by pure empirism we now apply our full knowledge of natural science, physics and meteorology in particular, and attempt to fit in, the experience gained in whatever part of the world into one pattern of a general validity. A prediction of the beneficial effects of irrigation and sprinkling or of drainage in the opposite case when there is a surplus of water, can then be made for countries for which no empirical data exist, and better estimates will be possible in other cases.

It is nowadays well recognized that water stress on plants does not only occur in arid climates but that it is often also an important factor in limiting yield in climates which are considered as wet.

In my country, for instance, it has been estimated that a considerable increase in yield of grassland as well as of arable crops will result if the water stress, which normally occurs in the months of July and August is removed. In the new plans to protect our country against the sea by partly closing the delta of the rivers Rhine and Meuse a reservoir of fresh water will be formed from which water for agriculture can be withdrawn. In making the plans for this very costly and difficult project the expected beneficial effects for agriculture have been taken into account. But here, as well as in other, less spectacular, projects the need of reliable methods to calculate water consumption in relation to crop yields has badly been felt.

We hope that the present meeting will materially contribute to fill this gap. Dr. Penman's introduction "Evaporation as an agricultural phenomenon" will 
serve as a basis of discussion for the numerous experiments on water consumption carried out in different climates under different conditions.

In addition to the discussions on evaporation other aspects of physics in agriculture will be dealt with. This again is of great importance for agricultural engineering. If I may compare the various engineering sciences with trees rooted in a soil consisting of the different compounds of natural science and of economy, it appears that the tree of agricultural engineering is growing in a soil in which a fixation of the compounds of natural science takes place. Physics seems to be even far less soluble than chemistry and biology. At any rate agricultural engineering has up till now not made use of physics to a similar degree as for instance mechanical engineering or chemical engineering. Its direct influence is mainly restricted to some specialized subjects as drainage and flow of groundwater and to the construction of special instruments. Its indirect influence is much greater, so for instance via mechanical engineering in the construction of agricultural machinery. It is important that physicists concerned with agriculture should now consider the possibilities which the modern development of physics has to offer to agriculture of the present and to agriculture of the future. In what direction agriculture of the future will develop is difficult to predict; it may be that the soil and even the plant itself will become less important for the production of food than they are at present but physics will most probably become more important for agricultural engineering whatever its future development will be.

Plant and soil are, however, still very important for food production at the moment. Our Ministry of Agriculture has offered field trips to two of our most characteristic districts for present day's agriculture in the Netherlands. Some further trips and excursions have been arranged to various parts of our country for the participants and their ladies which may give you an impression of life and of nature in the Netherlands.

Ladies and gentlemen, In my capacity as President of the Board of Governors of the Agricultural University I wish to emphasize that we appreciate it highly that the Laboratory of Physics and Meteorology of our University has been chosen for this meeting. I can assure you that the presence of so many experts from so many countries in the centre of agricultural science of the Netherlands is greatly valued by us. I wish to express my thanks to those who by their joint effort, have made this "Informal Meeting" possible, in particular to Dr. Schofield, to Dr. Penman and to Prof. van WIjk and his coworkers.

I hope, that this meeting will have all the results you are expecting from it and that the personal contact may lead to further cooperation also in other fields of primary importance for agriculture. I further hope that our foreign guests will enjoy their visit to our country as much as we are happy to have them with us and I now declare the meeting opened. 